\title{
Düşük hızlı ve küçük güçlü rüzgar türbinleri için kalıcı mıknatıslı senkron generatör tasarımı
}

\author{
Oktay KARAKAYA ${ }^{1,2, *}$, Batın DEMIRCAN², Murat Erhan BALCI ${ }^{2,3}$ \\ ${ }^{1}$ Balıkesir Üniversitesi, Bigadiç Meslek Yüksekokulu, Elektrik ve Enerji Bölümü, Bigadiç, Balıkesir \\ ${ }^{2}$ IŞBiR Elektrik San. A.Ş., Araştırma ve Geliștirme Bölümü, Altteylül, Balıkesir \\ ${ }^{3}$ Balıkesir Üniversitesi, Mühendislik Fakültesi, Elektrik-Elektronik Müh. Böl., Çağış kampüsü, Balıkesir
}

Geliş Tarihi (Received Date): 08.07.2020

Kabul Tarihi (Accepted Date): 24.02.2021

$\ddot{O} z$

Bu makalede, küçük güçlü düşük hızlı rüzgar türbinleri için radyal akılı kalıcı mıknatıslı senkron generatörlerin (KMSG'lerin) tasarımı ile Ansys Maxwell yazılım ortamında modellenmesi ve performans analizi üzerine örnek bir çalışma sunulmuştur. Bu örnek çalışmada, öncelikle analitik ifadeler kullanılarak; hedeflenen anma değerlerine sahip bir KMSG tasarımı yapılmıştır. Devamında, Ansys Maxwell yazılım ortamında iki boyutlu modelleme yaklaşımıyla, tasarımın, yüklenme oranı değişimine bağlı olarak gerilim etkin değeri, gerilim toplam harmonik bozulma değeri, akım etkin değeri ve verim performans parametrelerinin değişimi, ayrıca milin dönme hızının değişimine bă̆lı olarak bu dört performans parametresinin yanı sıra üretilen azami aktif güç değerinin değişimi analiz edilmiştir.

Anahtar kelimeler: Kalıcı mıknatısl senkron generatör, rüzgar türbini, tasarım, SEY analizi.

\section{Design of permanent magnet synchronous generator for low speed and small power wind turbines}

\begin{abstract}
In this paper, an exemplary study on the design of radial flux permanent magnet synchronous generators (PMSGs) for small power-low speed wind turbines and its

\footnotetext{
*Oktay KARAKAYA, karakaya@balikesir.edu.tr, https://orcid.org/0000-0003-3871-1724

Batın DEMIRCAN, batindemircan@gmail.com, https://orcid.org/0000-0002-0765-458X

Murat Erhan BALCI, mbalci@balikesir.edu.tr, https://orcid.org/0000-0001-8418-8917
} 
modelling and performance analysis in Ansys Maxwell software is presented. In this exemplary study, firstly, the design is obtained by using analytical expressions. Subsequently, the two-dimensional model of the design is provided in Ansys Maxwell software. Thus, the variation of the voltage effective value, voltage total harmonic distortion value, current effective value and efficiency parameters of the same design depending on the loading ratio, and the variation of these four parameters and maximum output active power depending on the speed are evaluated.

Keywords: Permanent magnet synchronous generator, wind turbine, design, FEM analysis.

\section{Giriș}

Günümüzde, yenilenebilir enerji temelli elektrik üretim birimleri, şebeke besleme noktasına uzak tüketicilerin elektrik ihtiyacının çevreci ve maliyet verimli bir şekilde karşılanması bakımından önemli bir seçenek haline gelmiştir [1-3]. Bununla birlikte, şebeke bağlantı noktasından uzak yerlerdeki küçük tüketicilerin beslenmesi amacıyla kurulan yenilenebilir enerji üretim birimleri; genellikle rüzgar türbinleri, fotovoltaik enerji üretim birimleri ve küçük su türbinleri olarak planlanmaktadır [4-7]. Ayrıca, bu yenilenebilir enerji temelli üretim birimlerinin, yine aynı amaçla; melez [8,9] ve dizel generatör destekli $[10,11]$ kullanımına ilişkin sistemler literatürde çalışılmıştır.

Rüzgar türbini topolojileri, sabit hızlı, sınırlı değişken hızlı ve değişken hızlı olmak üzere üç ana sınıfa ayrılabilir [12-14]. Değişken hızlı rüzgar türbinleri, generatör milinin türbine bağlantı tipine göre; çok kademeli dişli kutulu, tek kademeli dişli kutulu ve dişli kutusuz (doğrudan sürüşlü) olmak üzere üç alt sınıfa sahiptir [12, 13]. Ayrıca, değişken hızlı rüzgar türbinleri, sahip oldukları güç dönüştürücünün boyutuna göre kısmi ve tam boyutlandırılmış güç dönüştürücülü rüzgar türbinleri olarak literatürde anılmaktadır [14].

Rüzgar türbinlerinde (RT) yaygın olarak kullanılan generatör tipleri: (i) sabit hızlı RT'ler için sincap kafesli asenkron generatör (SKAG), (ii) sınırlı değişken hızlı RT'ler için bilezikli asenkron generatör (BAG), (iii) çok kademeli dişli kutulu değişken hızlı RT'ler için SKAG, çift beslemeli asenkron generatör (ÇBAG), geleneksel elektriksel uyartımlı senkron generatör (ESG) ve kalıcı mıknatıslı senkron generatör (KMSG), (iv) tek kademeli dişli kutulu değişken hızlı RT'ler için ÇBAG ve KMSG ile (v) doğrudan sürüşlü değişken hızlı RT'ler için ESG ve KMSG'dir. Sınırlı değişken hızlı RT'lerde; BAG'ların rotor sargı uçlarına bağlı güç elektroniği devresiyle rotor direnç ayarı yapılarak senkron hızın azami $\pm \% 10$ 'u kadar değişim aralığında hız ayarlanabilirken, ÇBAG bulunan değişken hızlı RT'lerde; generatörün rotor sargı uçlarıyla şebeke arasına bağlı kısmi (türbin gücünün \%30’u kadar anma güçte) boyutlandırılmış güç dönüştürücü devresiyle senkron hızın $\pm \% 30$ 'u kadar aralıkta hız ayarı yapılabilir. SKAG, ESG ve KMSG bulunan değişken hızlı RT'lerde ise; generatörün terminalleri ile şebeke arasına bağlı tam boyutlandırılmış güç dönüştürücüyle tam hız ayarı gerçekleştirilebilir [12, 13].

Doğrudan sürüşlü değişken hızlı rüzgar türbinlerinde kullanılan ESG ve KMSG arasında yapılan karşılaştırmadan, aynı güç değeri için KMSG'nin daha hafif, daha küçük hacimde, daha düşük maliyetli ve daha yüksek enerji verimliliğine sahip olduğu ifade edilebilir. Tek kademeli dişli kutulu değişken hızlı rüzgar türbinlerinde kullanılan ÇBAG ve KMSG arasında yapılan karşılaştırma ise; aynı güç değeri için yine KMSG'nin daha 
hafif, daha küçük hacimli ve daha yüksek enerji verimliliğine sahip seçenek olmakla birlikte maliyetinin de daha yüksek olduğunu göstermektedir [12].

Bütün bu avantajlar neticesinde, KMSG'ler, literatürde yapılan çalışmalarda, küçük güçlü tüketiciler ve mikro şebekelerin ihtiyacını karşılamak için tasarlanan düşük hızlı doğrudan sürüşlü rüzgar türbinlerinde yaygın olarak tercih edilmiştir [15-19].

Kalıcı Mıknatıslı Senkron Makineler (KMSM'ler) üretilen akının doğrultusuna göre radyal, eksenel ve çapraz akılı olmak üzere üç sınıfa ayrılmaktadır. Bununla birlikte, diğer iki tipe göre daha basit yapıda, daha güvenilir ve üretimleri daha pratik olması sebebiyle radyal akılı KMSM'ler, gerek motor gerekse generatör olarak daha fazla tercih edilmektedir [20-22]. Ayrıca, KMSM'lerin, mıknatısın rotor yüzeyindeki konumuna göre yüzeye montajlı ve rotor içine yerleştirilmiş mıknatıslı tipleri [22], rotorun statorun içinde veya dışında konumlandırılması bakımından iç rotorlu ve dış rotorlu tipleri [23] mevcuttur.

Elektrik makine tasarımındaki genel durumda olduğu gibi KMSG tasarımı için de hassasiyeti sebebiyle, literatürde en önde gelen tasarım aracı, sonlu elemanlar yöntemi veya sonlu elemanlar yöntemi temelli çözüm yapan paket yazılımlardır. Ancak, aşırı hesap yüküne sahip olması ve dolayısıyla uzun analiz süreleri gerektirmesi, sonlu elemanlar yönteminin (SEY) önemli bir dezavantajıdır [24, 25]. Bu dezavantaj sebebiyle, literatürdeki çalışmalarda, genellikle, tasarımın tümüyle SEY temelli analizlerle gerçekleştirilmesinden kaçınılmıştır. Manyetik eşdeğer devre [26, 27] veya kapalı form analitik ifadelerle $[25,28,29]$ tasarımların ön boyutlandırmaları yapılmış, devamında ise; bu boyutlandırmaların teyit edilmesi ve iyileştirilmesi SEY analizleriyle gerçekleştirilmiştir.

$\mathrm{Bu}$ makalede, düşük hızlı ve küçük güçlü rüzgar türbinleri için radyal akılı KMSG tasarımı ve Ansys Maxwell yazılım ortamında tasarımın doğrulanması ile performans analizi üzerine örnek bir çalışma sunulmuştur. Bu örnek çalışmada, öncelikle analitik ifadeler kullanılarak; hedeflenen anma değerlerine sahip bir KMSG tasarımı yapılmıştır. Devamında, bu tasarımın iki boyutlu modeli Ansys Maxwell [30] yazılımında oluşturulmuştur. $\mathrm{Bu}$ model kullanılarak, tasarımın; yüklenme oranı değişimine bağlı olarak gerilim etkin değeri, gerilim toplam harmonik bozulma değeri, akım etkin değeri ile verim performans parametrelerinin değişimi, ayrıca hız değişimine bağlı olarak bir önceki analizde dikkate alınan dört performans parametresinin yanı sıra üretilen azami aktif güç değerinin değişimi analiz edilmiştir.

\section{Tasarım ve modelleme}

$\mathrm{Bu}$ kısımda, tasarımın elde edilmesinde kullanılan analitik ifadeler sunulmuş ve tasarımın Ansys Maxwell yazılım ortamında oluşturulan 2 boyutlu modeli tanıtılmıştır. Çalışma kapsamında anma (plaka) değerleri; $5 \mathrm{~kW}, 200$ devir/dakika (dev./dak.), $400 \mathrm{~V}$ ve $\eta=\% 91$ olan bir KMSG'nin tasarımı hedeflenmiştir.

\subsection{Analitik ifadelerle tasarımın elde edilmesi}

KMSG'nin tasarımında, literatürde yaygın olarak bilinen analitik ifadelere dayalı boyutlandırma yöntemlerinden biri olan ve kaynak [31]'de sunulan yöntem dikkate alınmıştır. Bu yönteme göre sırasıyla; (i) rotor boyutları ve stator-rotor arası hava aralığı, 
(ii) stator sargılarına ilişkin parametreler, (iii) stator oyuğunun boyutları ile (iv) stator/rotor boyunduruk genişliği, mıknatısın boyutları ve stator boyutları hesaplanır.

$\mathrm{Bu}$ sıralamaya göre; ilk olarak rotor boyutları ve stator-rotor arası hava aralığının belirlenmesi safhasında;

- Hedeflenen generatör tasarımının nominal güç değeri $(P)$, verim $(\eta)$ ve saniye başına ölçülen nominal devir $(n)$ parametreleri dikkate alınarak, generatör şaftına uygulanacak nominal tork değeri $(T)$;

$$
T=\frac{P / \eta}{2 . \pi \cdot n}
$$

- Tasarımda izin verilen teğetsel gerilme değeri $\left(\sigma_{\text {Ftan }}\right)$ ve $T$ parametrelerine göre, rotorun hacmi $\left(V_{r}\right)$;

$$
V_{r}=\frac{\mathrm{T}}{2 \cdot \sigma_{\text {Ftan }}}
$$

- Nominal frekans $(f)$ ve $n$ cinsinden, kutup çifti sayısı $(p)$;

$$
p=\frac{f}{n}
$$

- $\quad$ 'ye bağlı olarak $\chi$ boyutsal oranı;

$$
\chi=\frac{\pi \cdot \sqrt{p}}{4 \cdot p}
$$

- $\quad \chi$ ve $V_{r}$ 'ye bağlı olarak rotor çapı $\left(D_{r}\right)$;

$$
D_{r}=\sqrt[3]{\frac{4 \cdot V_{r}}{\pi \cdot \chi}}
$$

- $\quad \chi$ ve $D_{r}$ cinsinden çekirdeğin eşdeğer uzunluğu $\left(l^{\prime}\right)$;

$$
l^{\prime}=\chi \cdot D_{r}
$$

- $\quad$ 'nin bir fonksiyonu olan stator ile rotor arasındaki hava aralığının uzunluğu $(\delta)$;

$$
\delta=\frac{0,18+0,006 \cdot P^{0,4}}{1000}
$$

- $\quad D_{r}$ ve $\delta$ cinsinden, stator iç çapı $\left(D_{S}\right)$;

$$
D_{s}=D_{r}+2 . \delta
$$

- $\quad l$ ve $\delta$ değerlerinden, rotor nüvesinin net uzunluğu $(l)$;

$$
l=l^{\prime}-2 . \delta
$$

hesaplanır. 
İkinci tasarım adımı olarak, stator sargılarına ilişkin parametrelerin belirlenmesi safhasinda;

- Generatör faz sayısı $(m)$ ile seçilen kutup- faz başına oyuk sayısı $(q \geq 1)$ dikkate alınarak, stator oyuk sayısı $(Q)$;

$$
Q=2 \cdot \pi \cdot m \cdot q
$$

- $D_{S}$ ve $Q$ parametrelerine göre, stator oyuk adımı $\left(\tau_{u}\right)$ ve stator kutup adımı $\left(\tau_{P}\right)$;

$$
\begin{gathered}
\tau_{u}=\pi \frac{D_{s}}{Q} \\
\tau_{P}=\pi \frac{D_{s}}{2 . p}
\end{gathered}
$$

- Tipik olarak 0.8 ile 1.05 Tesla aralığında seçilen, hava boşluğundaki temel frekans ak1 yoğunluğunun tepe değeri $\left(B_{1 \text { peak }}\right)$ ve mıknatısların rotor yüzeyinde kapladığ 1 alanın rotor yüzey alanına oranı $\left(\alpha_{P M}\right)$ cinsinden, mıknatıslar tarafından üretilen ak1 yoğunluğunun maksimum değeri $\left(B_{\max }\right)$;

$$
B_{\max }=\frac{\pi \cdot B_{1 \text { peak }}}{4 \cdot \sin \left(\frac{\pi \cdot \alpha_{P M}}{2}\right)}
$$

- $\quad m, Q, p$ ve sarım adımına $\left(w_{\tau p}\right)$ bağlı olarak, sargı faktörü $\left(k_{w}\right)$;

$$
k_{w}=\frac{2 \cdot \sin \left(\frac{\pi}{2} \cdot w_{\tau p}\right) \sin \cdot\left(\frac{\pi}{m \cdot 2}\right)}{\frac{Q}{m \cdot p} \sin \left(\frac{\pi \cdot p}{Q}\right)}
$$

- $\quad B_{\max }, \tau_{P}, l^{\prime}, \alpha_{P M}$, makinanın nominal açısal hızı $(\omega)$, stator faz sargı uçlarında boşta çalışma şartlarında indüklenmesi istenen gerilim değeri $\left(E_{P M}\right)$ ve sarg1 faktörü $\left(k_{w}\right)$ parametrelerine bağlı olarak, faz başına sarım sayısı $(N)$;

$$
N=\frac{\sqrt{2} \cdot E_{P M}}{\omega \cdot B_{\max } \cdot k_{w} \cdot l^{\prime} \cdot \tau_{p} \cdot \alpha_{P M}}
$$

- $\quad N, m, Q$ ve sarımdaki paralel kol sayısına ( $a$ ) göre oyuk başına sarım sayısı $\left(z_{Q}\right)$;

$$
z_{Q}=2 \cdot a \cdot m \frac{N}{Q}
$$

hesaplanır.

Bu tasarım safhasının sonunda, iki katmanlı sarımlarda oyuktaki iletken sayısının çift sayı olması gerekliliğine dikkat edilmelidir. Buna göre, revize edilmiş iletken sayısına $\left(z_{Q S}\right)$ göre $B_{\max }$ Denklem (17) ile yeniden hesaplanmalıdır:

$B_{\max }=\frac{z_{Q}}{z_{Q S}} B_{\max }$

Üçüncü tasarım adımı olarak, stator oyuklarının boyutlandırılması safhasında; 
- Tipik olarak 1.6 ile 2 Tesla arasında seçilen statordaki diş akı yoğunluğu $\left(B_{\text {dapp }}\right)$, nüve paketleme faktörü $\left(k_{F e}\right)$ ve daha önceki adımlarda belirlenen diğer tasarım parametreleri $\left(\tau_{u}, l^{\prime}, l, B_{\max }\right)$ cinsinden, stator diş genişliği $\left(b_{d}\right)$;

$b_{d}=\frac{l^{\prime} \cdot \tau_{u}}{k_{F e} \cdot l} \frac{B_{\max }}{B_{\text {dapp }}}$

- $\quad m, P$, generatörün hedeflenen güç faktörü $(\cos \varphi)$ ve faz-nötr anma gerilimi $\left(U_{s p h}\right)$ değerlerine göre, anma akımı $\left(I_{S}\right)$;

$$
I_{s}=\frac{P}{m \cdot U_{s p h} \cdot \cos \varphi}
$$

- Tipik olarak 4 ile $8 \mathrm{~A} / \mathrm{mm}^{2}$ arasında seçilen sargi iletkeni akım yoğunluğu $\left(J_{s}\right)$, $I_{S}$ ve $a$ ' ya bağlı olarak, bir iletkenin oyukta kapladığı alan $\left(S_{c S}\right)$ ve çap1 $\left(D_{c S}\right)$;

$$
\begin{aligned}
& S_{c s}=\frac{I_{s}}{a \cdot J_{s}} \\
& D_{c s}=\sqrt{\frac{4 . S_{c s}}{\pi}}
\end{aligned}
$$

- $\quad z_{Q}, S_{c s}$ ve stator yuvasına ait doldurma faktörü $\left(k_{C u s}\right)$ parametrelerinden, oyuktaki iletkenlerin kapladığ 1 toplam alan $\left(S_{c u s}\right)$;

$S_{c u s}=\frac{z_{Q} \cdot S_{c s}}{k_{C u s}}$

- Şekil 1'de verilen oyuk yapısı için, tasarımcı tarafından seçilen; oyuk açıklığ $1\left(b_{1}\right)$, oyuk izolasyon malzemesinin kalınlığ1 $\left(h_{3}, h_{6}\right)$, oyuk kama kalınlığ $1\left(h_{2}\right)$ sarg1 katmanları arasındaki yalıtkanın kalınlığı $(h)$, oyuk ağzı diş kalınlığı $\left(h_{1}\right)$ ve oyuk yapı yüksekliği $\left(h_{5}\right)$ parametreleri yanı sıra $b_{\mathrm{d}}, Q$ ve $D_{s}$ parametrelerine bağlı olarak, $b_{4}, b_{4 c}, b_{5 c}$ ve $b_{5}$ boyutlar1;

$$
\begin{aligned}
& b_{4}=\frac{\pi\left[D_{S}+2\left(h_{1}+h_{2}\right)\right]}{Q}-b_{d} \\
& b_{4 c}=b_{4}+\frac{2 \cdot \pi \cdot h_{3}}{Q}-2 h_{6} \\
& b_{5 c}=b_{4 c}+\frac{2 \cdot \pi \cdot h_{5}}{Q} \\
& b_{5}=b_{5 c}+2 \cdot h_{6}
\end{aligned}
$$

hesaplanır.

Stator oyuk boyutlandırma adımında, Denklem (22) ve (27)'den hesaplanan $S_{\text {cus }}$ değerleri eşit olana kadar $h_{5}$ parametresi güncellenir;

$$
S_{c u s}=\left(\frac{b_{4 c}+b_{5 c}}{2}\right) h_{5}+\frac{\pi}{8} b_{5 c}^{2}
$$


Bu adımda, son olarak; $h_{4}$ değeri ve toplam stator oyuk alanı $\left(S_{\text {slot }}\right)$ bulunur:

$$
\begin{aligned}
& h_{4}=h_{5}+\frac{b_{5 c}}{2} \\
& S_{\text {slot }}=b_{1} \cdot h_{1}+h_{2}\left(\frac{b_{4}}{2}+\frac{b_{1}}{2}\right)+h_{3}\left(b_{4}+\frac{\pi \cdot h_{3}}{Q}\right)+h_{5}\left(\frac{b_{4}+b_{5}}{2}\right)+\frac{\pi}{8} b_{5 c}^{2}
\end{aligned}
$$

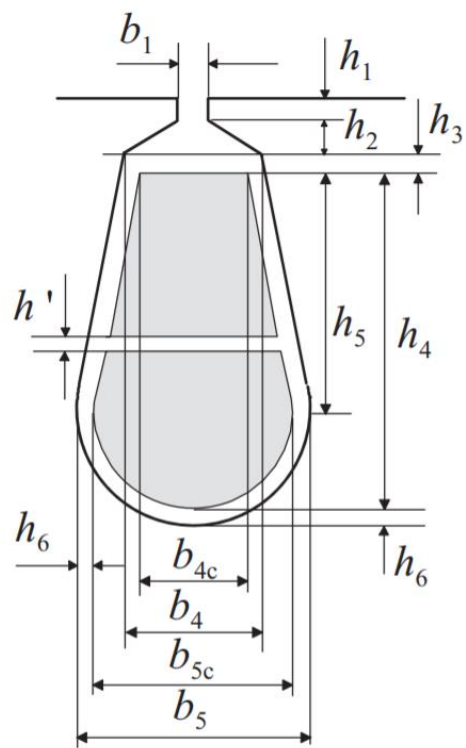

Şekil 1. Oyuk boyutlandırılması [31].

Dördüncü ve son tasarım adımında, stator ve rotor boyunduruğunun genişliği, mıknatısın boyutları ve stator boyutlarının belirlenmesi için;

- $\quad B_{\max }, \alpha_{P M}, \tau_{p}$.ve $l^{\prime}$ parametrelerinin bir fonksiyonu olan hava boşluğunun manyetik akısının maksimum değeri $\left(\Phi_{\max }\right)$;

$$
\Phi_{\max }=\alpha_{P M} \cdot B_{\max } \cdot \tau_{p} \cdot l^{\prime}
$$

- Tasarımda kullanılan çekirdek malzemesinin B-H eğrisi dikkate alınarak stator ve rotor boyunduruklarındaki maksimum akı yoğunlukları $\left(B_{y s}, B_{y r}\right), k_{F e}$ ve $l$ parametrelerinden, stator ve rotor boyunduruklarının yükseklikleri $\left(h_{y s}, h_{y r}\right)$;

$$
\begin{aligned}
& h_{y s}=\frac{\Phi_{\max }}{2 \cdot k_{F e} \cdot l \cdot B_{y s}} \\
& h_{y r}=\frac{\Phi_{\max }}{2 \cdot k_{F e} \cdot l \cdot B_{y r}}
\end{aligned}
$$

- Eşdeğer hava aralığg $1\left(\delta_{e}\right)$;

$$
\delta_{e}=\left[\frac{\tau_{u}}{\tau_{u^{-}}\left[\frac{2}{\pi}\left[\operatorname{atan}\left[\frac{b_{1}}{2 \delta}\right]-\frac{2 \delta}{b_{1}} \ln \left[\sqrt{1+\left(\frac{b_{1}}{2 \delta}\right)^{2}}\right]\right]\right]}\right] \delta
$$


- $B_{\max }, \delta_{e}$ ve havanın manyetik geçirgenliği $\left(\mu_{0}=4 \pi 10^{-7} \mathrm{H} / \mathrm{m}\right)$ değerlerinden, hava boşluğunun manyetik gerilimi $\left(U_{m \delta e}\right)$;

$U_{m \delta e}=\frac{B_{\max }}{\mu_{0}} \delta_{e}$

- Nüve malzemesinin B-H eğrisinde (Şekil 2) maksimum akı yoğunluğuna karşılık gelen manyetik alan şiddeti $\left(H_{d}\right), h_{3}$ ve $h_{5}$ parametreleri cinsinden, stator dişindeki manyetik gerilimi $\left(U_{m d s}\right)$;

$U_{m d s}=H_{d}\left(h_{3}+h_{5}\right)$

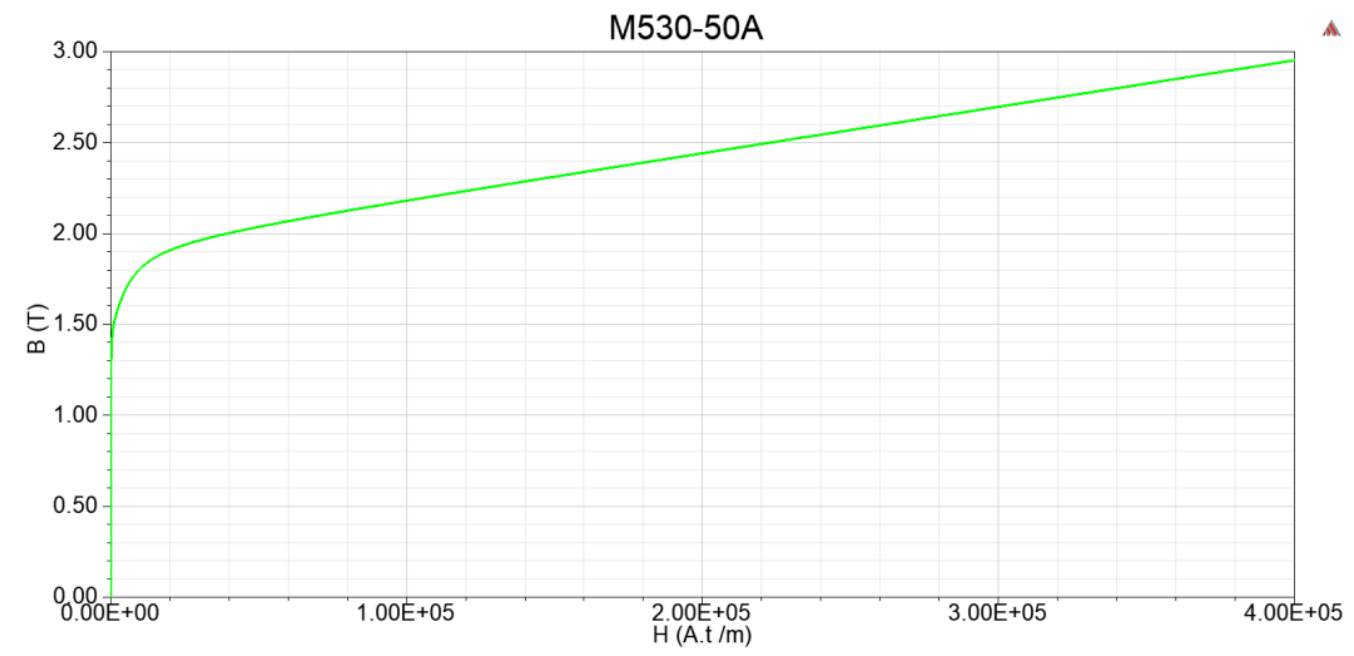

Şekil 2. Stator ve rotor sac malzemesinin BH eğrisi

- Ortalama stator boyunduruk çapı $\left(D_{y s}\right)$;

$D_{y s}=D_{s}+2\left(h_{1}+h_{2}+h_{3}+h_{4}+h_{6}\right)+h_{y s}$

- $\quad D_{y s}, \quad p$, çekirdek malzemesinin B-H eğrisinden stator boyunduruğundaki maksimum akı yoğunluğuna (1.5 ile $1.7 \mathrm{~T}$ ) karşılık gelen manyetik alan şiddeti değeri $\left(H_{y \text { maxs }}\right)$ ve Şekil 3'de verilen $c$-By eğrisinden stator boyunduruğundaki maksimum akı yoğunluğuna karşılık gelen katsayıya $\left(c_{S}\right)$ bağlı olarak, stator boyunduruğundaki manyetik gerilim $\left(U_{m y s}\right)$;

$U_{m y s}=c_{s} . H_{y \operatorname{maxs}} \frac{\pi \cdot D_{y s}}{2 p}$ 


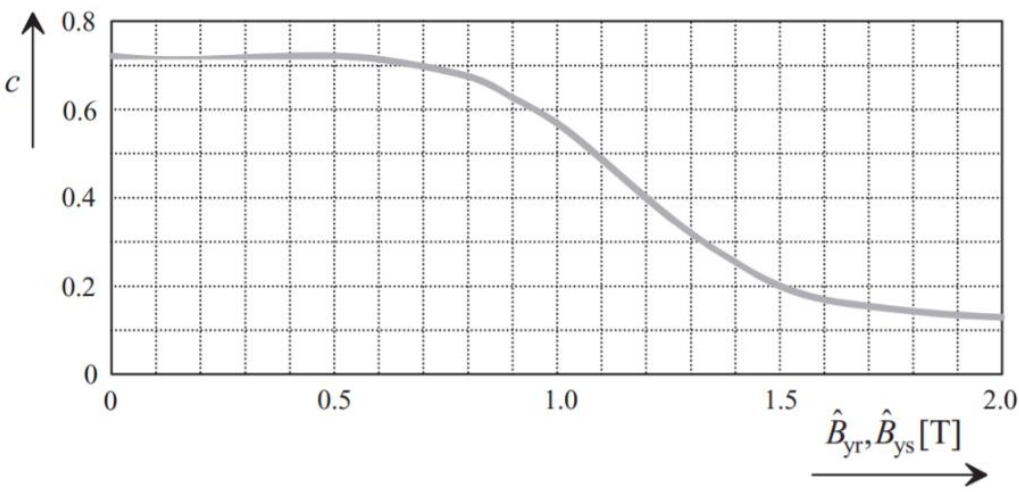

Şekil 3. Boyunduruk manyetik gerilimini belirlemek için kullanılan c katsayısı ile boyunduruk maksimum akı yoğunluğu arasındaki ilişki [31].

- $U_{m \delta e}, U_{m d s}, U_{m y s}, D_{r}, h_{y r}, p$, miknatısın akı yoğunluğu $\left(B_{P M}\right)$, çekirdek malzemesinin $\mathrm{B}-\mathrm{H}$ eğrisinden rotor boyunduruğundaki maksimum ak1 yoğunluğuna (1.5 ile 1.7 T) karşıllı gelen manyetik alan şiddeti değeri $\left(H_{\text {ymaxr }}\right)$, mıknatısın manyetik alan şiddeti $\left(H_{c}\right)$ ve Şekil 3'deki eğride rotor boyunduruğundaki maksimum akı yoğunluğuna karşılık gelen katsayı $\left(c_{r}\right)$ değerlerinden, mıknatısın kalınlığ $1\left(h_{P M}\right)$;

$$
h_{P M}=\frac{U_{m \delta e}+U_{m d s}+\frac{U_{m y s}}{2}+\frac{\pi \cdot c_{r} \cdot H_{y \max }\left(D_{r}-h_{y r}\right)}{4 p}}{H_{c}-\frac{H_{C}}{B_{r}} B_{P M}+\frac{\pi \cdot c_{r} \cdot H_{y \max }}{2 p}}
$$

- $\quad \alpha_{P M}$ ve $\tau_{P}$ 'nin çarpımından, mıknatısın genişliği $\left(w_{P M}\right)$;

$$
w_{P M}=\alpha_{P M} \cdot \tau_{P}
$$

- $\quad D_{r}, h_{P M}$ ve $h_{y r}$ değerlerinden, rotor boyunduruğunun ortalama çapı $\left(D_{y r}\right)$;

$$
D_{y r}=D_{r}+2 \cdot h_{P M}-h_{y r}
$$

- $D_{y s}$ ve $h_{y s}$ parametrelerinin toplamından, stator diş çap1 $\left(D_{s e}\right)$;

$$
D_{s e}=D_{y s}+h_{y s}
$$

- $\quad D_{y r}$ ve $h_{y r}$ parametrelerinin farkından, rotor iç çap1 $\left(D_{r i}\right)$;

$$
D_{r i}=D_{y r}-h_{y r}
$$

bulunur.

Buraya kadar özetlenen, tasarıma ilişkin hesaplamaların akış diyagramı Şekil 4'de sunulmuştur. 


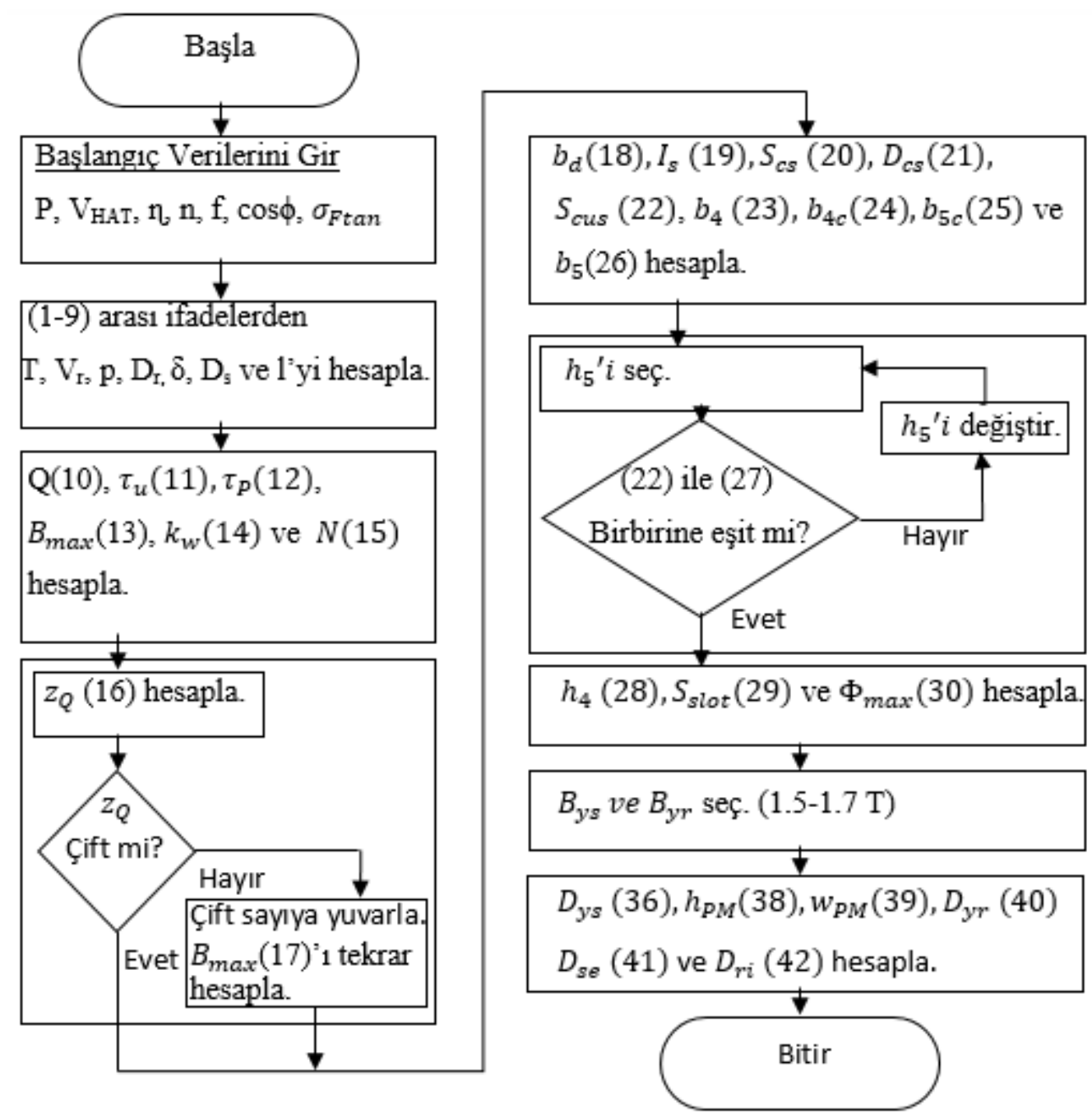

Şekil 4. Analitik hesaplamalar için akış şeması.

\subsection{Tasarımın Ansys Maxwell ortamında 2 boyutlu modellenmesi}

Çalışmanın bu aşamasında, “Ansys Maxwell” yazılımına, sırasıyla;

- Stator ile rotorun dış çapı, iç çapı ve uzunluğu,

- Stator oyuk boyutları, sarg1 ile ilgili parametreler ve malzemeler (stator nüvesi (M530-50A), sarg1 (bakır)),

- Rotor bünyesinde bulunan mıknatıs boyutları ile malzemeler (rotor nüvesi (M53050A), miknatıs (NdFe35)),

- Anma gücü, anma gerilimi, anma hızı ve çalışma sıcaklığı gibi, makine parametreleri girilerek, tasarım yazılıma tanıtılmıştır (Şekil 5).

Tasarlanan KMSG'nin kutup sayısı 30, stator oluk sayısı 90 ve mıknatıs kalınlığı 5 mm olup ürünün ticarileşmesi sebebiyle, diğer tasarım parametreleri bu çalışmada verilmeyecektir. Daha sonra, ANSYS Maxwell Circuit Editor araciyla, KMSG'nin 2 boyutlu (2B) modeline harici devre olarak dengeli saf omik yük bağlanarak yükte test gerçekleştirilmiştir (Şekil 6). Yük değeri yaklaşık $24 \Omega$ 'dur. 
DN ANSYS Electronics Deskeop - pmsg, $5 \mathrm{kw}$

1] File Edit View Project Drow Modeler Maxwell 2D Tools Window Help

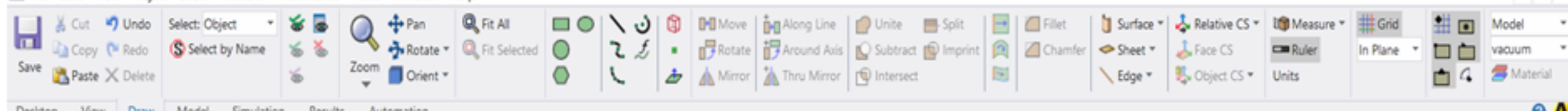

\begin{tabular}{l} 
Desktop View Drow Model Smulation Results Automation \\
\hline Model
\end{tabular}
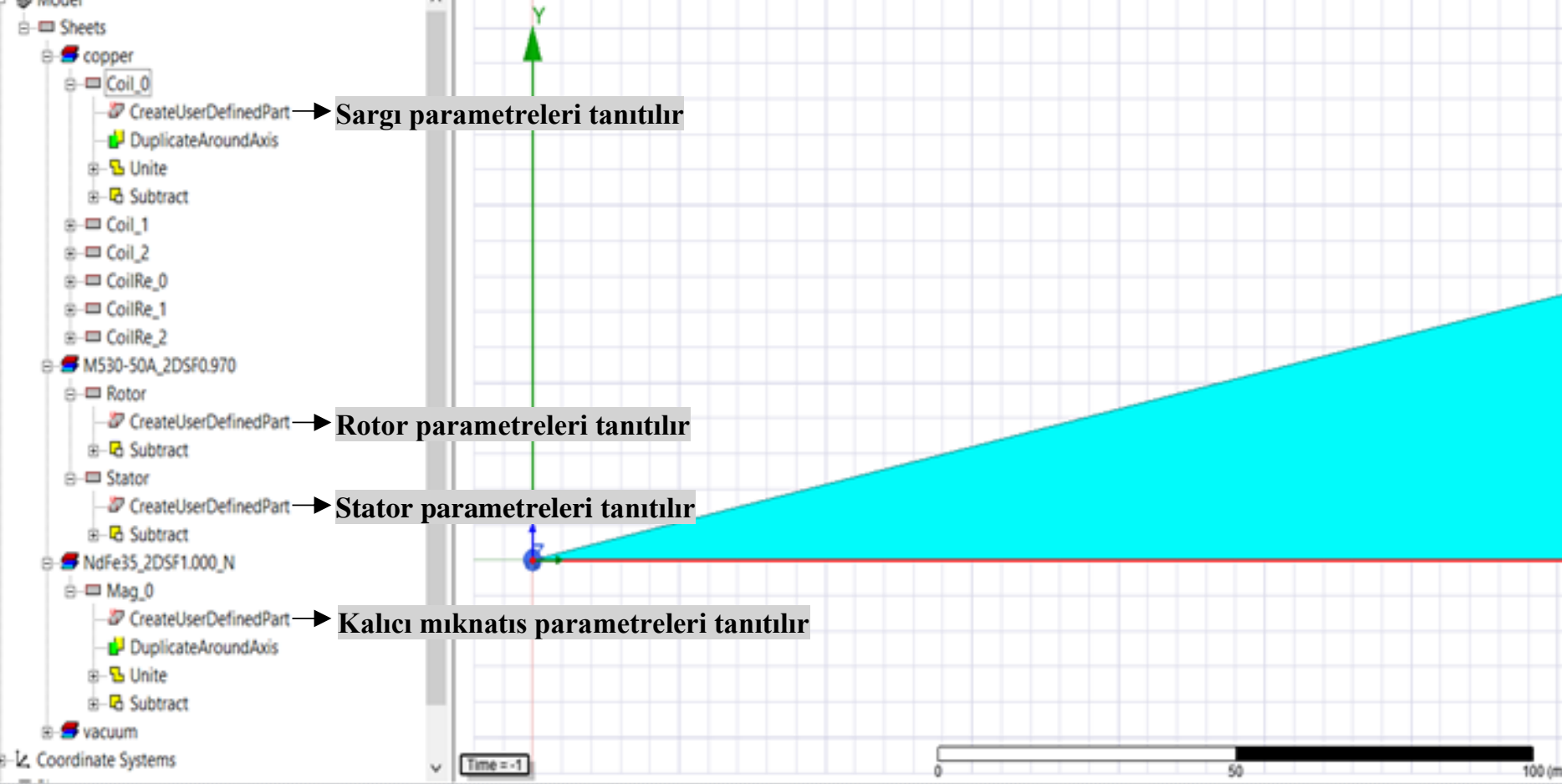

Şekil 5. Ansys Maxwell yazılımı 2 boyutlu model. 
प 1 File Edit View Project Draw Schematic Maxwell Circuit Tools Window Help

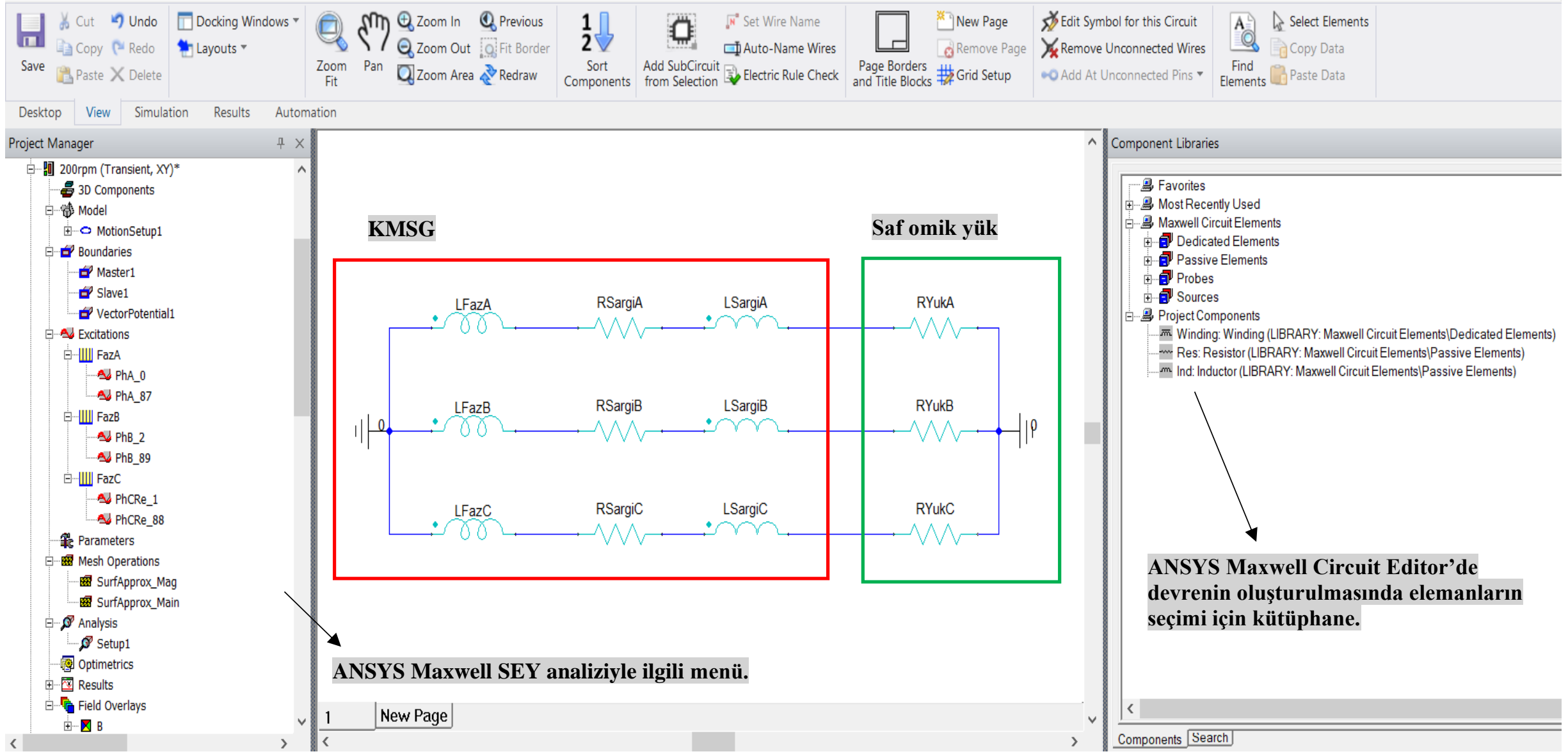

Şekil 6. ANSYS Maxwell Circuit Editor'de yüklenme testi için oluşturulan devre. 


\section{Analiz sonuçları}

KMSG tasarımı Ansys Maxwell yazılımıyla, anma hızı (200 dev./dak.) boşta ve anma yükte $(5000 \mathrm{~W})$ çalışma durumları için benzetim yapılmıș ve generatör terminalinde gözlemlenen hat gerilimlerine ait dalga şekilleri sırasıyla Şekil 7 ve 8 'de verilmiştir.

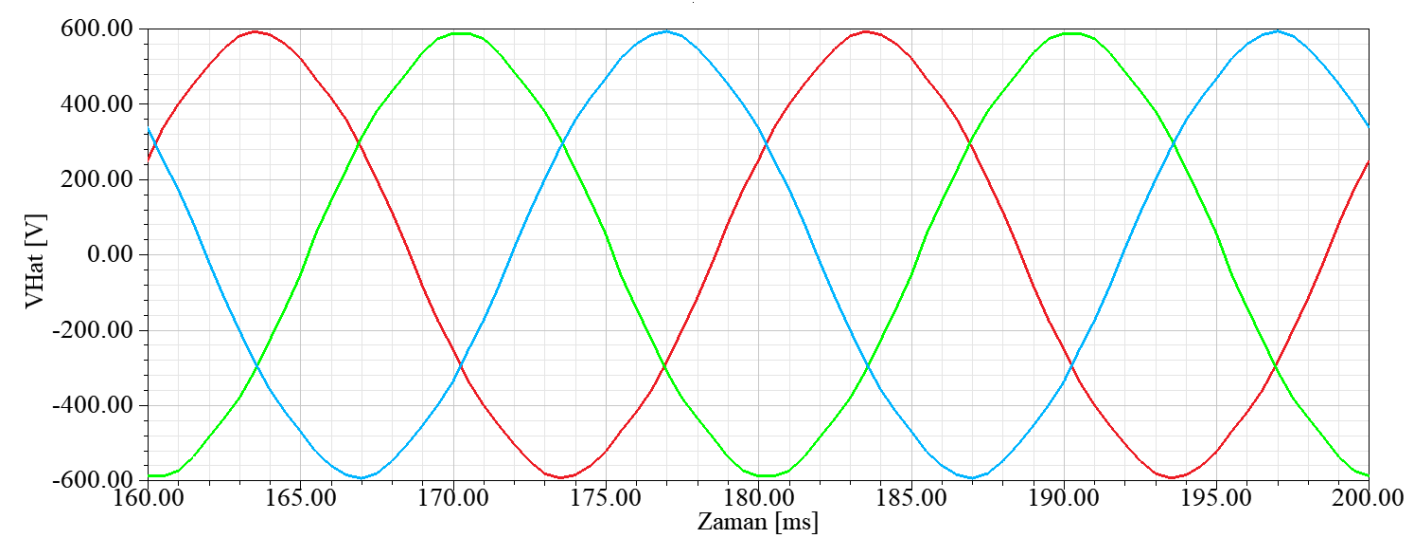

Şekil 7. Anma hızı ve boşta çalışma durumunda hat gerilimlerinin zamana göre değişimi.

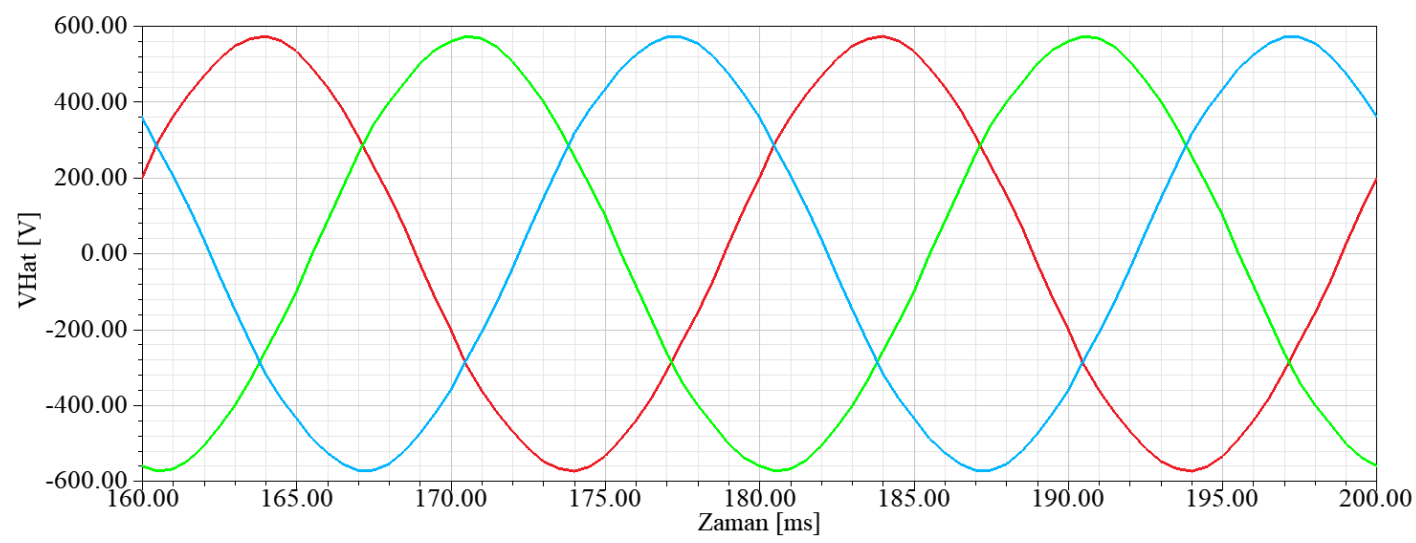

Şekil 8. Anma hızı ve anma yüklenme çalışma durumunda hat gerilimlerinin zamana göre değişimi.

$\mathrm{Bu}$ şekillerden, tasarlanan generatörün her iki çalışma durumunda, terminal hat gerilimlerinin dengeli ve sinüzoidal dalga formlarına sahip olduğu, ayrıca gerilimlerin tepe değerlerinin yaklaşık olarak; boşta çalışma durumunda $583 \mathrm{~V}$ ve anma yükte çalışma durumunda 568 V olduğu görülmektedir.

Tasarımda anma yüklenme şartlarında, $\mathrm{t}=100 \mathrm{~ms}$ anında manyetik akı yoğunluğunun dağılımı Şekil 9'da verilmiştir. Bu şekilden, anlık manyetik akı yoğunluğunun; hava boşluğunda 1 Tesla, mıknatıslara karşılık gelen stator dişlerinde 1.75 Tesla ve stator boyunduruğunda 2.07 Tesla civarlarında olduğu ifade edilebilir. 


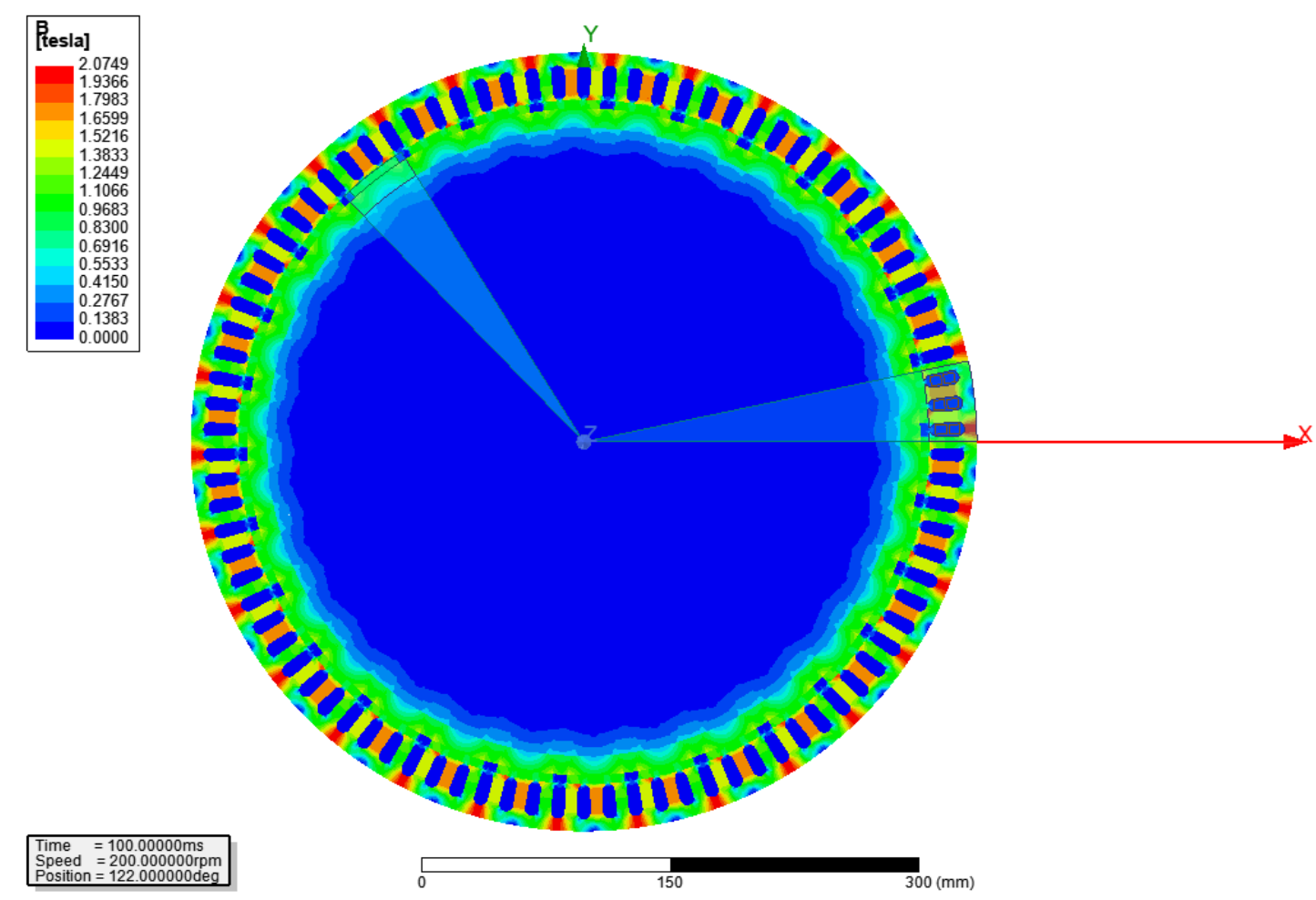

Şekil 9. t=100 ms anında gözlemlenen manyetik akı yoğunluğu dağılımı.

Yüklenme oranının, KMSG'nin performansına etkisini incelemek amacıyla; \%10 ile $\% 100$ arasında \%10'luk artışlarla yüklenme oranlarında $(Y O)$; verim $(\eta)$, hat gerilimi etkin değeri $\left(V_{\mathrm{Hat}}\right)$, toplam gerilim harmonik bozulma değeri $\left(T H D_{\mathrm{V}}\right)$ ve akım etkin değeri ( $\left.I_{\mathrm{Faz}}\right)$ hesaplanmıştır. Elde edilen $\eta$ - $Y O, V_{\mathrm{Hat}}-Y O, T H D \mathrm{v}-Y O$ ve $I_{\mathrm{Faz}}-Y O$ eğrileri sırasıyla Şekil 10, 11, 12 ve 13'de sunulmuştur.

Şekil 10'dan $\eta$ 'nin; $Y O$ 'nun \%10 değeri için \%82.1 olduğu, \%10-\%60YO aralığında artış gösterdiği ve maksimum değeri olan \%92.7'ye ulaştığ1, son olarak \%60-\%100 YO aralığında azaldığ görülmektedir.

Şekil 11'den generatörün boşta çalışma $(Y O=\% 0)$, yarı yüklenme $(Y O=\% 50)$ ve anma yüklenme $(Y O=\% 100)$ durumlarında, $V_{\text {Hat }}$ değerlerinin sirasıyla $412.04 \mathrm{~V}, 407.04 \mathrm{~V}$ ve $401.44 \mathrm{~V}$ olduğu, $V_{\text {Hat }}$ 'n $Y O$ ile doğrusal olarak azaldığı ve generatörün gerilim regülasyon oranının \%2.6 civarında olduğu ifade edilebilir.

Şekil 12 generatörün boşta çalışma durumunda $T H D$ v'nin en yüksek değerde (\%1.79) olduğunu, ayrıca $Y O$ artışıyla bu indisin azaldığını göstermektedir. Bu şekil, tasarlanan KMSG'nin terminal geriliminin IEEE Standard 519-2014 [32]'de tanımlanan sınır değer olan \%8'in altında $T H D_{\mathrm{v}}$ 'ye sahip olduğunu açıkça işaret etmektedir.

Şekil 13'den $Y O$ artışı ile $I_{\text {Faz' }}$ 'n doğrusal olarak arttığ 1 , $I_{\text {Faz }}$ değerinin yarım ve anma yüklenme durumlarında sırasıyla; 4.1 A ve 8.2 A olduğu görülmektedir. 


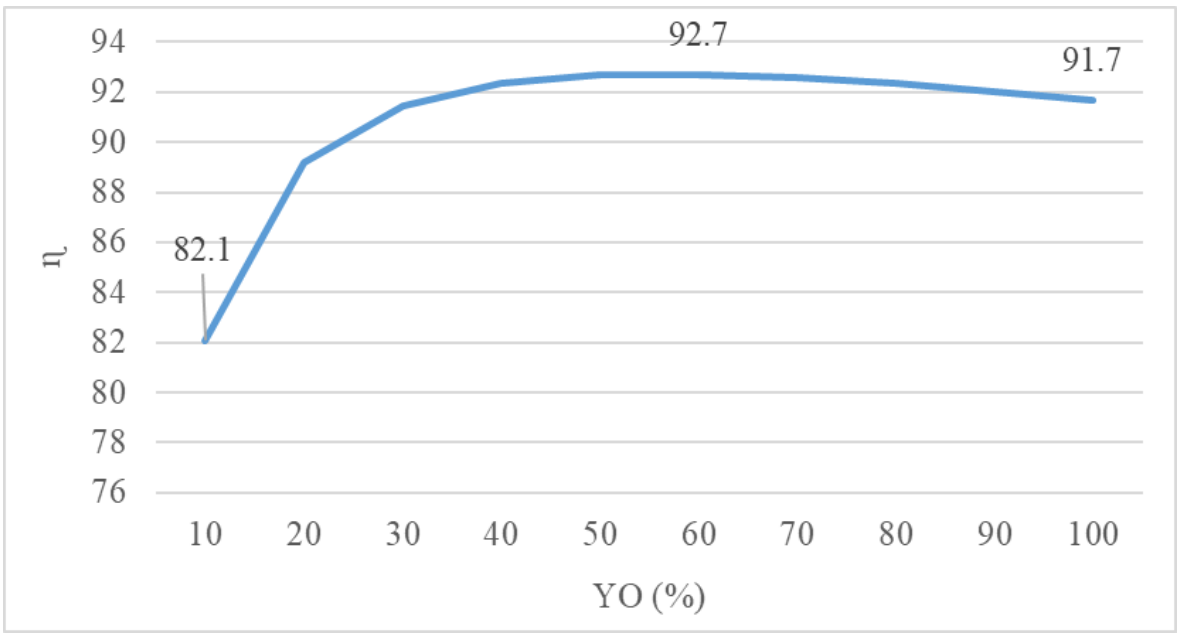

Şekil 10. $\eta$-YO eğrisi.

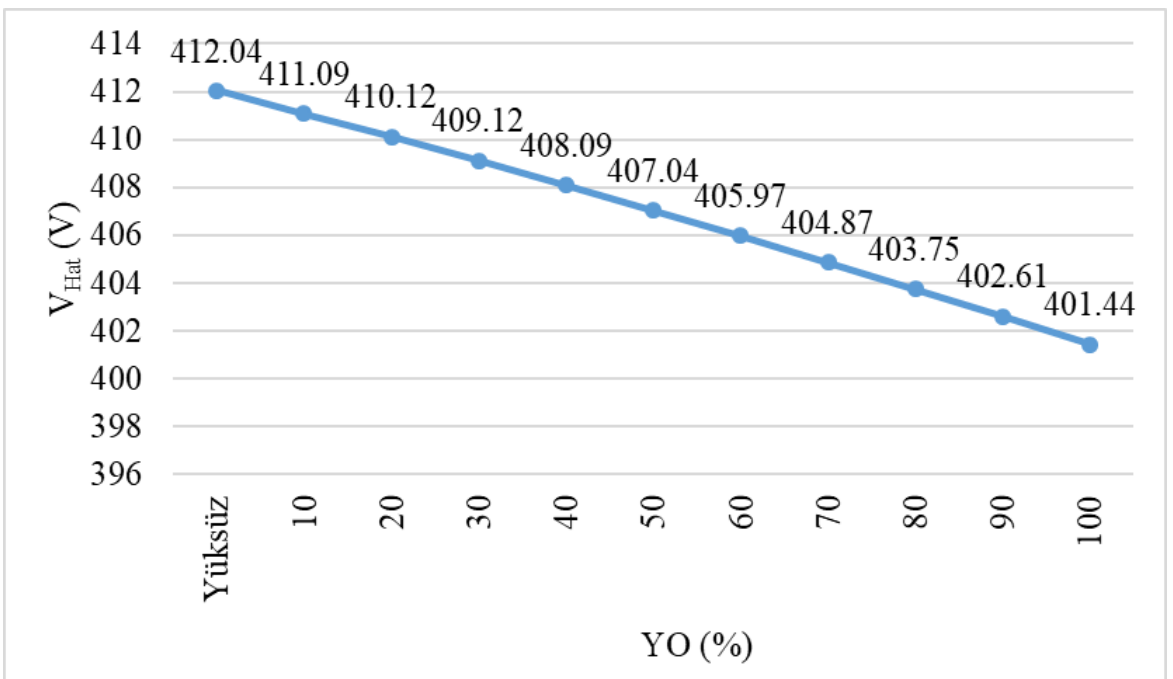

Şekil 11. $V_{\text {Hat }} Y O$ eğrisi.

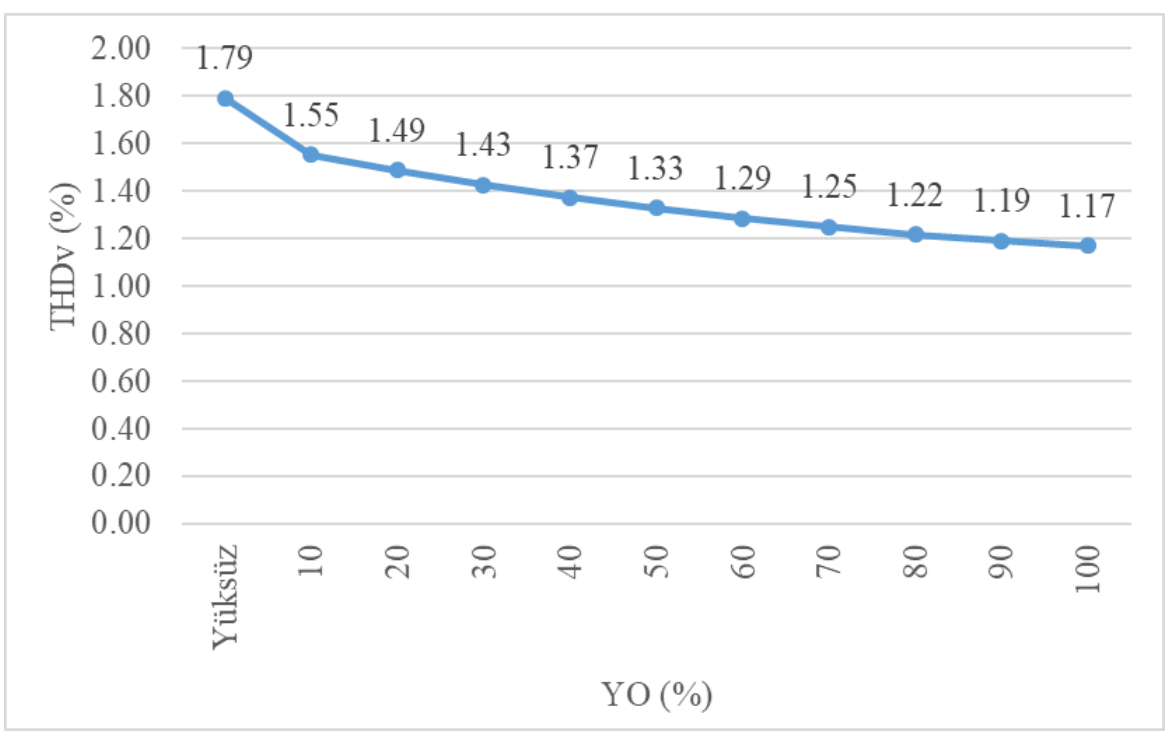

Şekil 12. $T H D_{\mathrm{v}}-Y O$ eğrisi. 


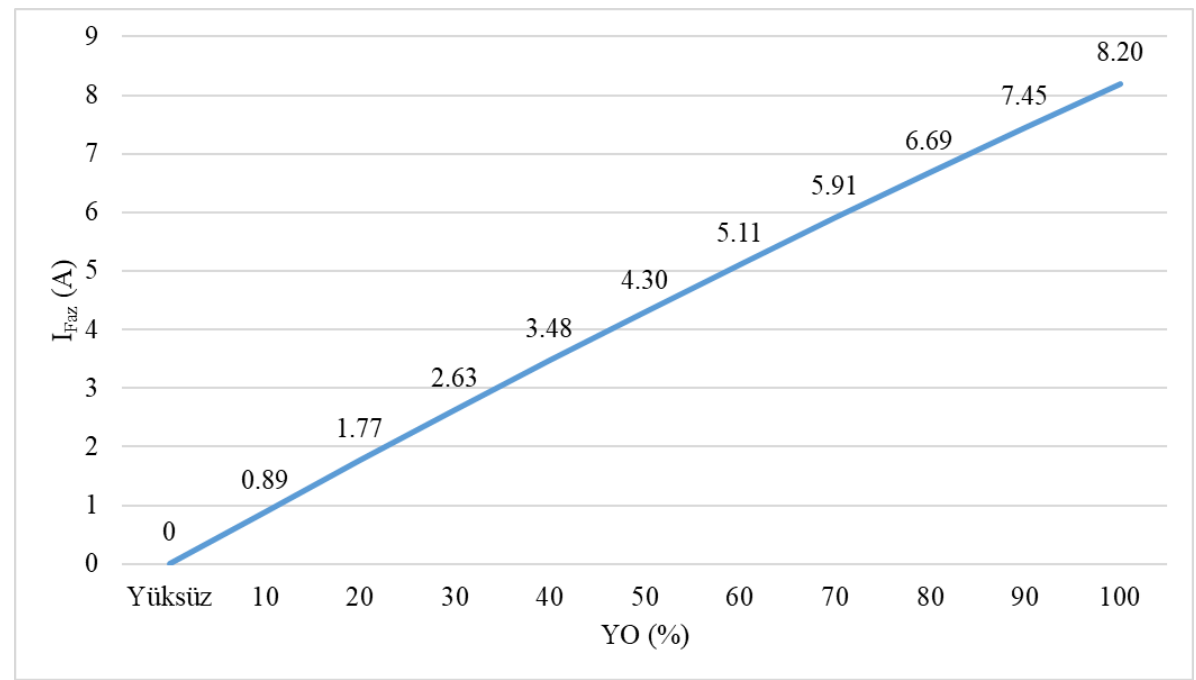

Şekil 13. $I_{\mathrm{Faz}}-Y O$ eğrisi.

Dakikadaki devir sayısı cinsinden milin dönme hızının (n) KMSG'nin performansına etkisini incelemek amaciyla; $n$; $20 \mathrm{dev}$./dak. ile $220 \mathrm{dev} . / \mathrm{dak}$. arasında $20 \mathrm{dev} . / \mathrm{dak} .{ }^{\prime} l 1 \mathrm{k}$ adımlarla arttırılmış ve $\eta-n, V_{\mathrm{Hat}^{-}} n, T H D_{\mathrm{V}^{-}} n, I_{\mathrm{Faz}^{-}} n$ ve aktif güç $(P)-n$ eğrileri sırasıyla Şekil $14,15,16,17$ ve 18 'de sunulmuştur.

Şekil 14'den $\eta$ 'nin; 20 dev./dak. ile 80 dev./dak. hız aralığında dikkate değer bir artış göstererek \%81.7'den \%90'a yükseldiği, geri kalan hız aralığında ise daha küçük bir artışla yaklaşık olarak \%91.7'ye ulaştığ 1 ifade edilebilir.

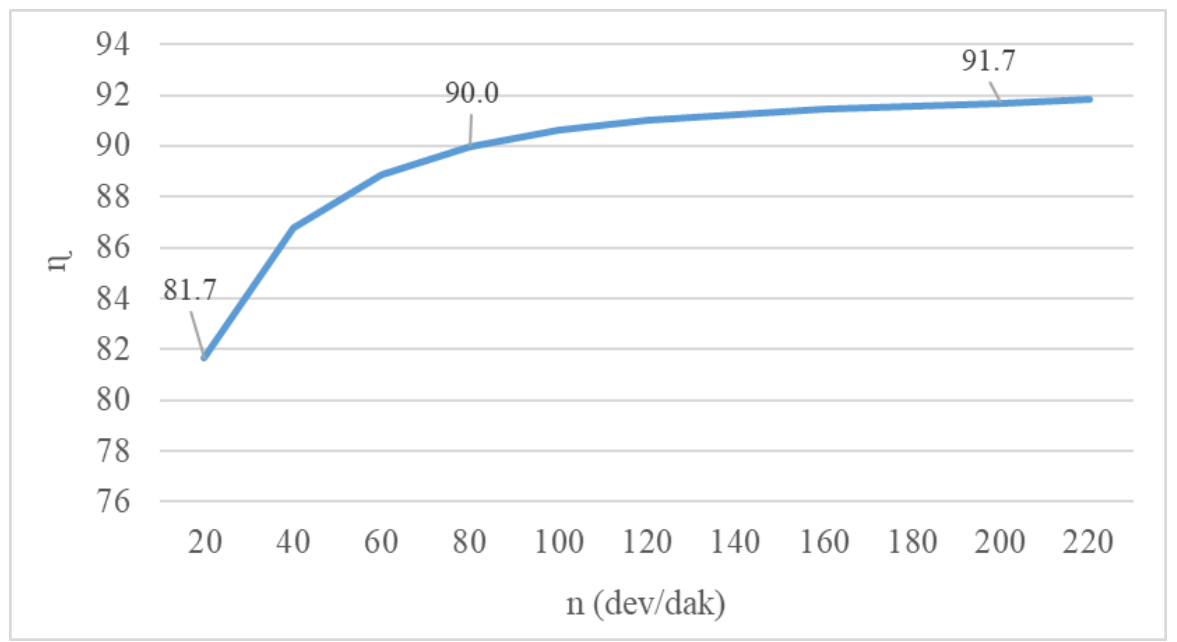

Şekil 14. $\eta$ - $n$ eğrisi. 
BAUN Fen Bil. Enst. Dergisi, 23(2), 434-454, (2021)

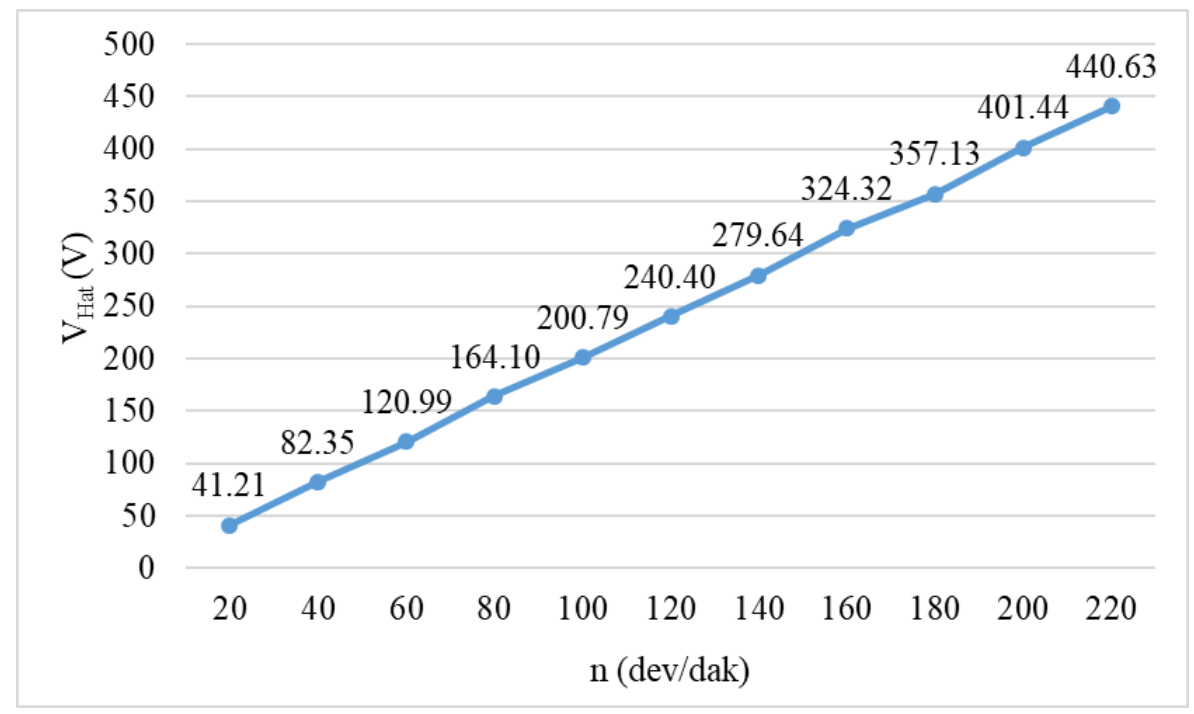

Şekil 15. $V_{\text {Hat }}-n$ eğrisi.

Şekil 15 ise $V_{\text {Hat }}$ 'n n ile doğrusal olarak artarak; çok düşük hız (n=20 dev./dak.) için 41.21 $\mathrm{V}$, anma hızın yarısı ( $n=100 \mathrm{dev} . / \mathrm{dak}$.) için $200.79 \mathrm{~V}$, anma hız ( $n=200 \mathrm{dev} . / \mathrm{dak}$.) için $401.44 \mathrm{~V}$ ve $n=220 \mathrm{dev} . / d a k$. için $440.63 \mathrm{~V}$ değerlerini aldığını göstermektedir.

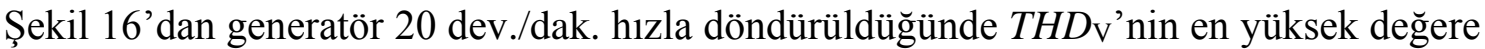
(\%1.63) sahip olduğu ve hızın artışıyla $T H D$ v'nin eksponansiyel şekilde azaldı̆̆ görülmektedir. Anma hızında ise $T H D_{\mathrm{V}} \% 1.17$ değerindedir. Bu eğriden, tasarlanan KMSG'nin terminal geriliminin tüm hız değerlerinde, IEEE Standard 519-2014'de tanımlanan sınır değerin altında $T H D$ v'ye sahip olduğu görülmektedir.

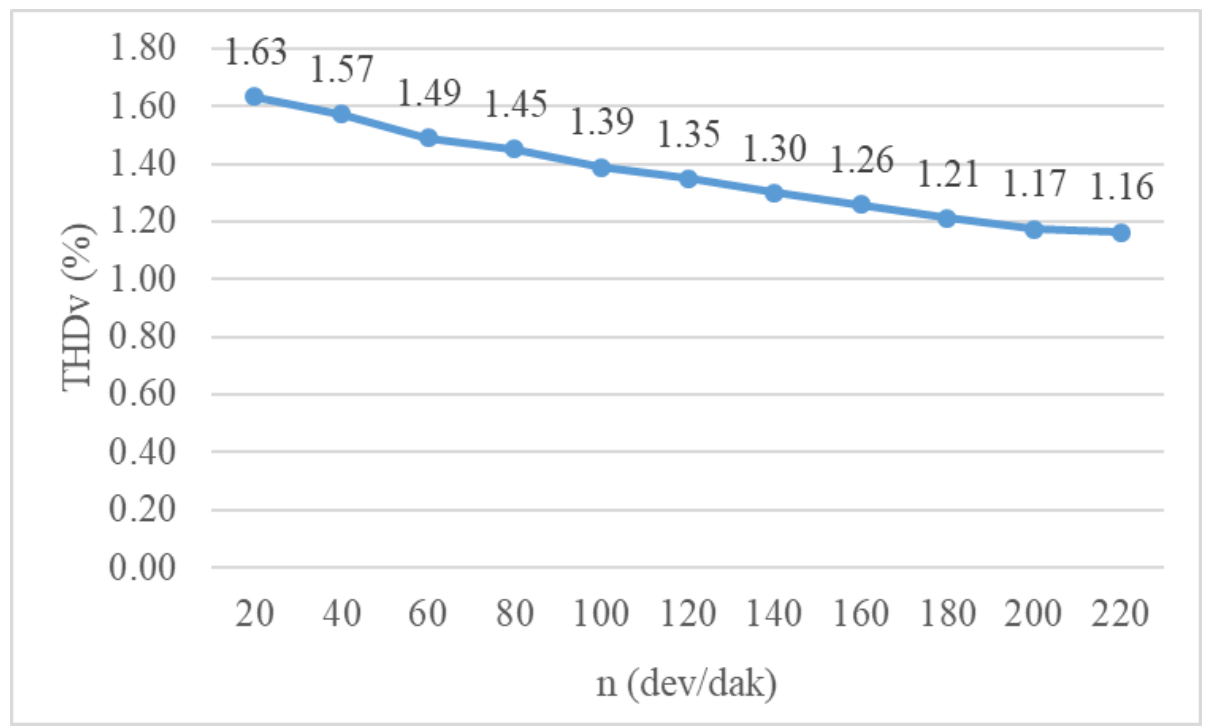

Şekil 16: $T H D_{\mathrm{V}}-n$ eğrisi. 


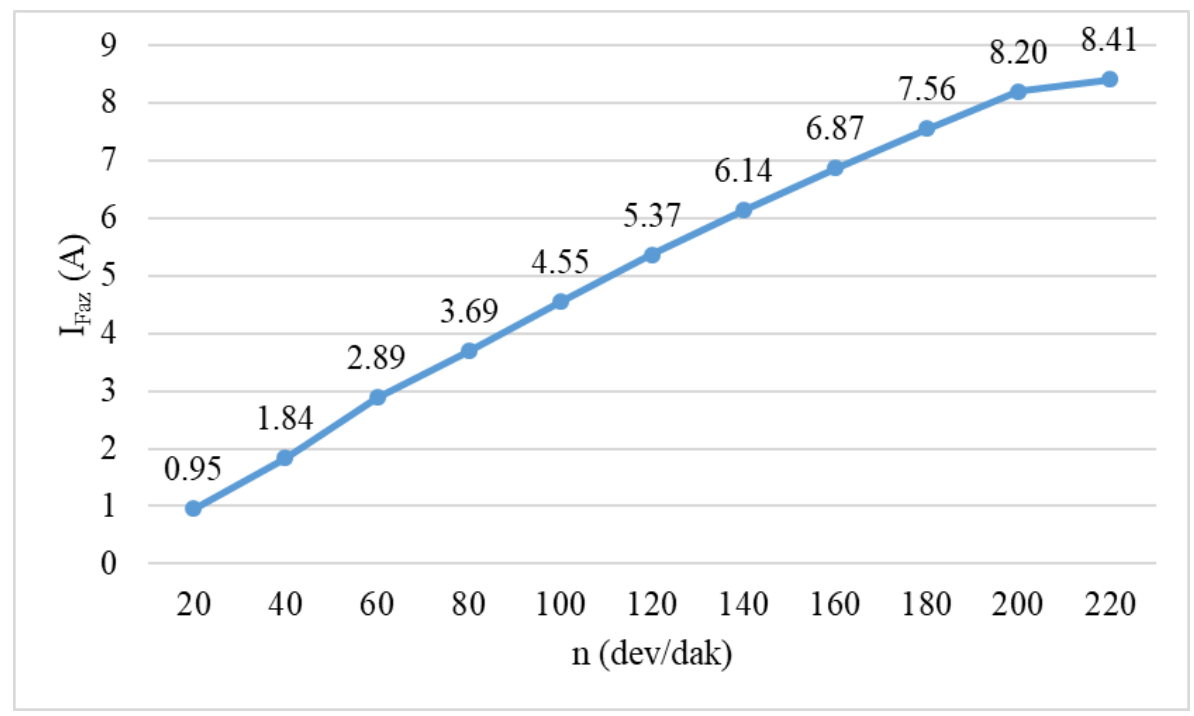

Şekil 17: $I_{\mathrm{Faz}}-n$ eğrisi.

Şekil 17 ise $I_{\text {Faz' }}$ 'n $n$ ile doğrusal olarak artarak; çok düşük hız (n=20 dev./dak.) için 0.95 A, anma hızın yarısı ( $n=100$ dev./dak.) için 4.55 A, anma hızı ( $n=200$ dev/dak) için 8.20 A ve $n=220 \mathrm{dev} . /$ dak. için 8.41 A değerlerini aldığını göstermektedir.

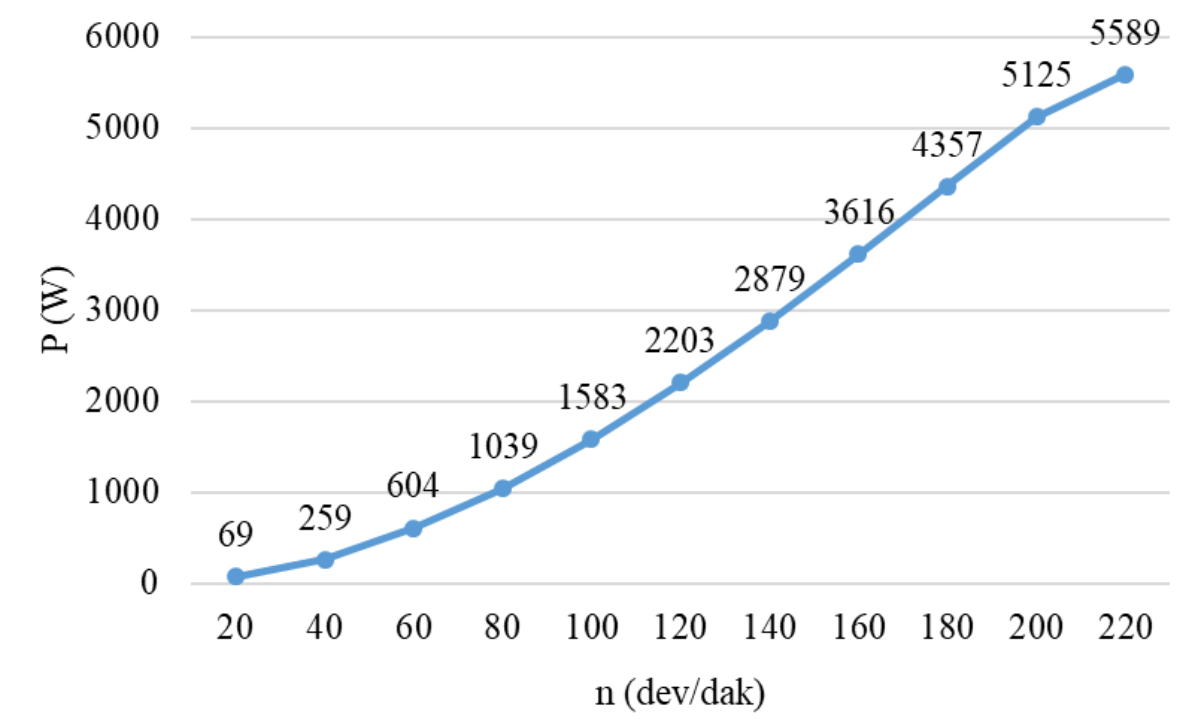

Şekil 18: $P-n$ değişim eğrisi.

Şekil 18'den $n=20$ dev./dak. için $69 \mathrm{~W}, n=100$ dev./dak. için $1583 \mathrm{~W}, n=200$ dev./dak. için $5125 \mathrm{~W}$ ve $n=220 \mathrm{dev}$./dak. için $5589 \mathrm{~W}$ değerlerinin gözlemlendiği dolayısıyla $P$ 'nin anma hızın yarısından sonra kayda değer bir şekilde arttığı sonucuna ulaşıımıştır.

\section{Sonuçlar ve tartışma}

Doğrudan sürüşlü bir başka deyişle dişli kutusuz değişken hızlı rüzgar türbinleri, şebekeden uzakta küçük güçlü tüketicilerin, düşük rüzgar hızlarında, verimli ve mekanik 
bakım gereksinimi düşük bir şekilde elektrik ihtiyacının karşılanması için yaygın olarak tercih edilen bir yenilenebilir enerji temelli üretim yöntemidir.

$\mathrm{Bu}$ makalede, düşük hızlı ve küçük güçlü rüzgar türbinleri için radyal akılı kalıcı mıknatıslı senkron generatörlerin (KMSG'lerin) tasarımı ile Ansys Maxwell yazılım ortamında modellenmesi ve performans analizi üzerine örnek bir çalışma sunulmuştur. Çalışmanın KMSG tasarım kısmında, sonlu elemanlar yöntemi temelli analizlerin uzun sürmesi sebebiyle, analitik yöntemle makinenin boyutları ve parametreleri belirlenmiştir. Daha sonra, bu boyutlar ve parametreler, Ansys Maxwell yazılımına tanitılarak 2 boyutlu model oluşturulmuştur. Son olarak; aynı yazılım kullanılarak, tasarlanan KMSG'nin performans analizleri gerçekleştirilmiştir.

Ansys Maxwell yazılımıyla yapılan performans analizlerinden, tasarımın analitik modelleme aşamasında hedeflenen makine anma değerlerine ulaştığı, ayrıca tasarımı gerçekleştirilen KMSG'nin; IEEE 519-2014 standardında tanımlı toplam gerilim harmonik bozulma sınırlamasına uyduğu, yüksek verim değerlerinde çalıştığı (\%92), gerilim regülasyon değerinin düşük seviyede olduğu (\%2.6) ve anma devrinin \%50'sinden büyük devirlerde anma gücüyle kıyaslandığında kayda değer güçler üretmeye başladığı sonuçlarına ulaşılmıştır.

Gelecekteki çalışmalarda, daha büyük güçler için çeşitli algoritmalar kullanılarak, optimal KMSG tasarımının yapılması planlanmaktadır.

\section{Teşekkür}

Bu çalışma, İŞBİR Elektrik San. A.Ş. Ar-Ge biriminde gerçekleştirilmiştir.

\section{Kisaltmalar}

\begin{tabular}{|c|c|}
\hline$K M S G$ & : Kalıcı mıknatıslı senkron generatör \\
\hline$S E Y$ & : Sonlu elemanlar yöntemi \\
\hline$K M S M$ & : Kalıcı mıknatıslı senkron makine \\
\hline$T H D$ & : Toplam harmonik distorsiyon \\
\hline$R T$ & : Rüzgar türbini \\
\hline$Y O$ & : Yüklenme oranı \\
\hline$S K A G$ & : Sincap kafesli asenkron generatör \\
\hline$B A G$ & : Bilezikli asenkron generatör \\
\hline$C ̧ B A G$ & : Çift beslemeli asenkron generatör \\
\hline$E S G$ & : Elektriksel uyartımlı senkron generati \\
\hline
\end{tabular}

\section{Kaynaklar}

[1] Brent, A. C. ve Kruger, W. J., Systems analyses and the sustainable transfer of renewable energy technologies: A focus on remote areas of Africa, Renewable Energy, 34(7), 1774-1781, (2009).

[2] Chauhan, A. ve Saini, R. P., Techno-economic optimization based approach for energy management of a stand-alone integrated renewable energy system for remote areas of India, Energy, 94, 138-156, (2016). 
[3] Boute, A., Off-grid renewable energy in remote Arctic areas: An analysis of the Russian Far East, Renewable and Sustainable Energy Reviews, 59, 1029-1037, (2016).

[4] Izadyar, N., Ong, H. C., Chong, W. T. ve Leong, K. Y., Resource assessment of the renewable energy potential for a remote area: A review, Renewable and Sustainable Energy Reviews, 62, 908-923, (2016).

[5] Shukla, R. D. ve Tripathi, R. K., Isolated wind power supply system using doublefed induction generator for remote areas, Energy Conversion and Management, 96, 473-489, (2015).

[6] Nafeh, E. S. A., Design and economic analysis of a stand-alone PV system to electrify a remote area household in Egypt, The Open Renewable Energy Journal, 2, 33-37, (2009).

[7] Ranjitkar, G., Huang, J. ve Tung, T., Application of micro-hydropower technology for remote regions, 2006 IEEE EIC Climate Change Conference, IEEE, 1-10, (2006).

[8] Bekele, G. ve Tadesse, G., Feasibility study of small hydro/PV/wind hybrid system for off-grid rural electrification in Ethiopia, Applied Energy, 97, 5-15, (2012).

[9] Khatib, T., Mohamed, A. ve Sopian, K., Optimization of a PV/wind micro-grid for rural housing electrification using a hybrid iterative/genetic algorithm: Case study of Kuala Terengganu, Malaysia, Energy and Buildings, 47, 321-331, (2012).

[10] Lal, D. K., Dash, B. B. ve Akella, A. K., Optimization of PV/wind/micro-hydro/ diesel hybrid power system in HOMER for the study area, International Journal on Electrical Engineering and Informatics, 3(3), 307, (2011).

[11] Saheb-Koussa, D., Haddadi, M. ve Belhamel, M., Economic and technical study of a hybrid system (wind-photovoltaic-diesel) for rural electrification in Algeria, Applied Energy, 86(7-8), 1024-1030, (2009).

[12] Li, H. ve Chen, Z., Overview of different wind generator systems and their comparisons, IET Renewable Power Generation, 2(2), 123-138, (2008).

[13] Cheng, M. ve Zhu, Y., The state of the art of wind energy conversion systems and technologies: A review, Energy Conversion and Management, 88, 332-347, (2014).

[14] Bhutto, D. K., Ansari, J. A., Bukhari, S. S. H. ve Chachar, F. A., Wind energy conversion systems (WECS) generators: A review, In 2019 2nd International Conference on Computing, Mathematics and Engineering Technologies, 1-6, Sukkur, Pakistan, (2019).

[15] Bisenieks, L., Vinnikov, D. ve Galkin, I., New converter for interfacing PMSG based small-scale wind turbine with residential power network, In 2011 7th International Conference-Workshop Compatibility and Power Electronics (CPE), IEEE, 354-359, (2011).

[16] Madescu, G., Mot, M., Biriescu, M., Greconici, M. ve Koch, C., Low speed PM generator for direct-drive wind applications, In 2011 IEEE EUROCONInternational Conference on Computer as a Tool, IEEE, 1-4, (2011).

[17] Alam, H. S., Irasari, P. ve Dewi, D. K., Analytical and numerical deflection study on the structure of $10 \mathrm{~kW}$ low speed permanent magnet generator, Journal of Mechatronics, Electrical Power, and Vehicular Technology, 3(2), 87-94, (2012). 
[18] Orlando, N. A., Liserre, M., Mastromauro, R. A. ve Dell'Aquila, A., A Survey of control issues in PMSG-based small wind-turbine Systems, IEEE transactions on Industrial Informatics, 9(3), 1211-1221, (2013).

[19] Tazi, K., Abbou, M.F. ve Abdi, F., Performance analysis of micro-grid designs with local PMSG wind turbines, Energy Systems, 1-33, (2019).

[20] Chen, A., Nilssen, R. ve Nysveen, A., Performance comparisons among radialflux, multistage axial-flux, and three-phase transverse-flux PM machines for downhole applications, IEEE Transactions on Industry Applications, 46(2), 779-789, (2010).

[21] Ahsanullah, K., Dutta, R. ve Rahman, M. F., Review of PM generator designs for direct-drive wind turbines, In 2012 22nd Australasian Universities Power Engineering Conference (AUPEC), IEEE, 1-6, (2012).

[22] Dorrell, D. G., Hsieh, M. F., Popescu, M., Evans, L., Staton, D. A. ve Grout, V., A review of the design issues and techniques for radial-flux brushless surface and internal rare-earth permanent-magnet motors, IEEE Transactions on Industrial Electronics, 58(9), 3741-3757, (2010).

[23] Arafat, M. Y., Murshed, M., Hasan, M. M. ve Razzak, M. A., Design aspects and performance analysis of inner and outer rotor permanent magnet alternator for direct driven low-speed wind turbine, In 2016 2nd International Conference on Advances in Electrical, Electronics, Information, Communication and BioInformatics (AEEICB), IEEE, 604-609, (2016).

[24] Yilmaz, M. ve Krein, P. T., Capabilities of finite element analysis and magnetic equivalent circuits for electrical machine analysis and design, In 2008 IEEE Power Electronics Specialists Conference, IEEE, 4027-4033, (2008).

[25] Kim, J. H. ve Sarlioglu, B., Closed-form method for multi-stage axial flux permanent magnet machine: design and analysis, Electric Power Components and Systems, 45(7), 785-797, (2017).

[26] Elosegui, I., Martinez-Iturralde, M., Rico, A. G., Florez, J., Echeverría, J. M. ve Fontan, L., Analytical design of synchronous permanent magnet motor/generators, In 2007 IEEE International Symposium on Industrial Electronics,1165-1170, (2007).

[27] Amuhaya, L. L. ve Kamper, M. J., Design analysis of a hybrid-PM synchronous generator for wind energy applications, In 2015 International Conference on the Domestic Use of Energy (DUE), IEEE, 163-167, (2015).

[28] Faqih, M. R., Sutedjo, S. ve Wahjono, E., Design and fabrication of a radial flux permanent magnet synchronous generator, In 2019 International Electronics Symposium (IES), IEEE, 644-649, (2019).

[29] Wang, T. ve Wang, Q., Optimization design of a permanent magnet synchronous generator for a potential energy recovery system, IEEE Transactions on Energy Conversion, 27(4), 856-863, (2012).

[30] A. N. S. Y. S. Maxwell, Low frequency electromagnetic field simulation, https://www.ansys.com/products/electronics/ansys-maxwell, (18.05.2020).

[31] Pyrhonen, J., Jokinen, T. ve Hrabovcova, V., Design of rotating electrical machines, John Wiley \& Sons, (2013).

[32] IEEE 519, IEEE recommended practices and requirements for harmonic control in electrical power systems, IEEE Standardı, (2014). 